\title{
ORTHOPRACTICE
}

\section{Rare disorders: instructions for care}

\section{Yves SOYER}

\author{
DCD, SQODF, AHU-PH Paris 7 - Hôpital Pitié-Salpétrière \\ Expert près de la Cour d'appel de Paris
}

After reading the last two issues of the Review dedicated to rare diseases, odontologists/orthodontists can no longer be unaware of the distinctive nature of these disorders called rare diseases.

We have to emphatically state once more how important the medical history and the clinical examination are when one of these pathologies is suspected.

\section{How should a practitioner respond when faced with a dental abnormality?}

The dental surgeon is an essential partner during all stages of the genetic consultation that determines the genetic aspects of the disorder and its mode of transmission.
The practitioner also evaluates the modalities of prevention and treatment and coordinates the multidisciplinary management plan for the patient and his family and suggests molecular diagnosis, and a genetic test if possible. When dealing with an isolated dental pathology, the dental surgeon is often the first consultant to diagnose these dental abnormalities, to interview the patients and their families and to make a systematic disease-specific examination (hair, skin, hands, face) of the patient. If the pathology appears to be isolated and hereditary, it is important to direct the patient and the family towards consultation for dental genetic disorders and to seek the advice of a geneticist. The patient and the family will all benefit from genetic counseling ${ }^{4}$.

\section{TWO SITUATIONS MAY ARISE:}

\section{The patient knows about the rare disease}

The practitioner can refer to the Orphanet.fr site and find detailed information concerning the rare disease carried by the patient.

Orphanet is the public reference portal for rare disorders and orphan medicines. Its objective is to help to improve the diagnosis, 
the management and the treatment of rare disorders.

We should emphasize that Orphanet is a French initiative that was created conjointly by INSERM and the Direction Générale de la Santé on January 1, 1997 within the framework of a "program of common interest," featuring a French language server, and opened to the public on January 1, 1998.

With free access, Orphanet offers a whole range of free and noteworthy services:

- an inventory of rare diseases and a classification of these diseases following the published expert classification;

- an encyclopedia of rare disorders;

- a service for diagnosis help that allows searches using signs and symptoms.

Furthermore, a free application is available on the App Store that gives access to all necessary information, with the subtabs "summary," "synthesis," "resources," (with emergency cards, articles for the general public, and recommendations for best practices).

The tab "consultations" makes it easy to find a consultation (name of the disorder, health professional, country, referral center, specialized consultations, genetic counseling, adult or child consultation, etc.).

Since the application is updated monthly, it will be a reliable source for the most recent data.

\section{When a rare disease is suspected}

The diagnosis must be precise, informative; it should be supported by the current scientific data and in addition to the oral health expertise from dentistry, it integrates biology and genetic development.

Sometimes, in the course of an examination during a routine consultation, if the practitioner suspects a family history and if the patient asks ("What is a genetic defect? What does it mean? Are these the only affected teeth? Can this defect be transmitted ...), the clinician must be able to formulate a diagnosis and it is strongly recommended that he be in contact with a specialized consultation $^{1}$, to collaborate with a geneticist who will assume responsibility for the family and set out in a neutral way the implications of these abnormalities, explaining that the current knowledge in this area is rapidly evolving. A dialog with a dento-geneticist colleague can also allow the practitioner to better identify the oral-dental implications of the disorder and to elaborate on an optimal management plan for his patient.

The treating practitioner will find all the information on the Phenodent.org site that will help him to direct his patient towards the two referral centers and/or the five treatment and diagnostic centers specializing in odontological malformations as well as the fourteen treatment and diagnostic centers for cleft lip and palate.

The site features synthetic files on oligodontia (Fig. 1), amelogenesis imperfecta, dentinogenesis imperfecta, early loss of the teeth or a single central incisor, for example. The file "Phenodent D(4)" (Diagnosing Dental Defects Database), a ten page file of data, will be a guide to spot the signs of dysmorphic phenotypes ${ }^{3}$. 


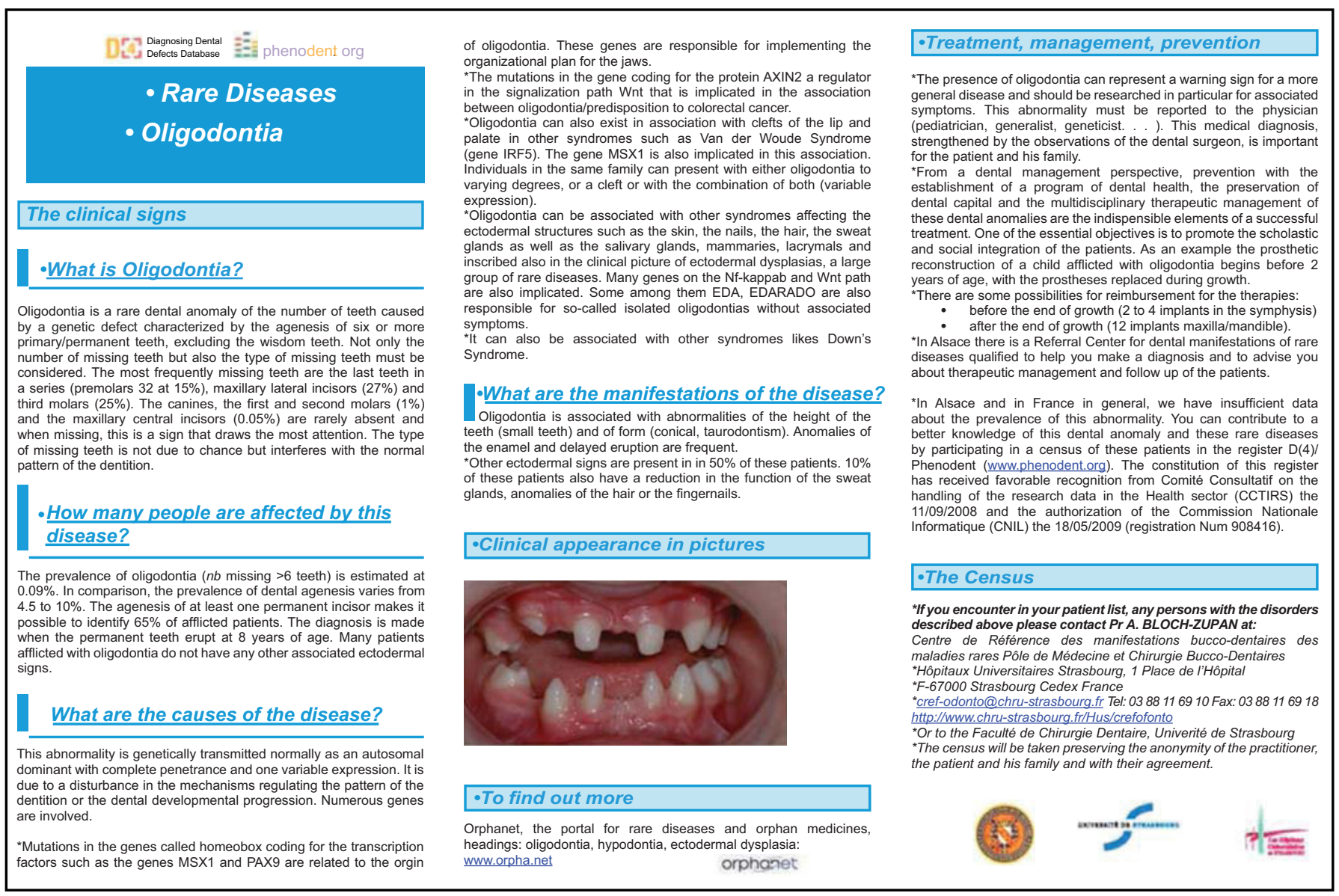

Figure 1

\section{WHO IS CONCERNED?}

The families of patients presenting with oral and dental developmental abnormalities whether it comes from a genetic predisposition or is induced by teratogenic action interfering with the phases of mineralization of the dental buds. Both affected and healthy members of a family are concerned.

The accepted method of observation or investigation is the following: after receiving a clear consent, dated, signed by the patient indicating his willingness to participate and to contribute to the project "Diagnosing dental defects," database, D(4)
Phenodent, the patient will be offered a standard orodental examination.

The clinical orodental examination includes:

- a record of the medical and orodental family history, as well as any previous oral or dental treatments of the patient;

- a clinical examination strictly speaking, conventional visual examination performed by a dental surgeon;

- a radiographic examination that conforms to the needs of the patient and to the existing regulations regarding 
the use of ionizing radiation in the context of practicing dentistry;

- collection of intra-oral and extra-oral digital photographs

- possible fabrication of study models.

The clinical examination successively analyzes the deciduous and then the permanent dentition. Each tooth is examined and individually scored for abnormalities of number, form and size (that constitutes in fact a continuum of anomalies), the structure of the tissues (enamel and dentine), dental eruption and position. Available indices will also be utilized. This approach makes it possible to logically establish the extent to which teeth and bone structures are involved and how the disorder has progressed, at first through the University of dentistry, and then with other consultations in and out of the hospital.

Patients with rare diseases are not only found in the referral centers and treatment and diagnostic centers of competence. More than 5,000 genetic syndromes are known, 700 have a dental/oral/craniofacial component and more than 250 present with a cleft palate in their clinical picture. Today the chromosomal location of more than 50 of these disorders is known and the genes have been discovered in more than 60 of these disorders presenting with craniofacial and dental phenotypes.

Even though it is not simple to identify them within the health care system, while fully respecting the free choice of the patient ${ }^{6}$, the dental and orthodontic practitioner is legally responsible for failing to recognize a rare disorder. There is a loss of opportunity for the patient if he does not compile a complete clinical file. A complete file is required to receive treatment for the agenesis of multiple teeth linked to a rare disorder ${ }^{5}$.

\section{BIBLIOGRAPHY}

1. Bloch-Zupan A. Génétique, la contribution de I'odontologie, Le Chirurgien-dentiste de France 2004;1184:30-36.

2. Boy-Lefevre $M L$, et al. Maladies rares et centres de référence. Rev Orthop Dento-Faciale 2013;47:345-353.

3. De La Dure-Molla M, Garrec P. Patients dysmorphiques : une relecture des signes cliniques mineurs vers le diagnostic. Rev Orthop Dento-Faciale 2013;47:355-371.

4. Flori E. Conseil génétique et anomalies dentaires. Journal d'Odonto-Stomatologie Pédiatrique 1997;7:165-168.

5. Prise en charge des agénésies dentaires multiples liées à une maladie rare chez l'enfant. www.ameli.fr

6. Soyer Y. Le libre choix du patient, Mémoire Master Droit de l'expertise appliqué à I'odontostomatologie, 2011 Univ Paris 8. 